\title{
Animal Models of Obsessive-Compulsive Disorder: Strain Differences
}

\author{
Taimon P. Maio, Guilherme B. Filgueiras, Daniel C. Cunha, Celio Estanislau \\ Department of General Psychology and Behavior Analysis, State University of Londrina, Londrina, Brazil \\ Email: celio.estanislau@gmail.com
}

Received 3 May 2014; revised 3 June 2014; accepted 10 June 2014

Copyright (C) 2014 by authors and Scientific Research Publishing Inc. This work is licensed under the Creative Commons Attribution International License (CC BY). http://creativecommons.org/licenses/by/4.0/ cc) (7) Open Access

\begin{abstract}
Obsessive-compulsive disorder (OCD) is characterized by obsessions (intrusive thoughts, images etc.) and compulsions (repetitive, stereotyped and perseverant acts). Animal models of OCD are specifically devoted to simulating compulsive features of the disorder. In OCD, compulsive behaviors are recognized as repetitive and maladaptive and symptoms relief can be experienced due to treatment with selective serotonin reuptake inhibitors. Many animal models of OCD are provided with some degree of validity. Genetically based differences in behavior in animal models of OCD are of great value, given that human OCD is reported to involve genetic factors. Some animal models of OCD were already used in studies for the evaluation of strain differences. These works were explored in the present review.
\end{abstract}

\section{Keywords}

Obsessive-Compulsive Disorder, Animal Models, Strain Differences, Individual Differences

\section{Introduction}

Obsessive-compulsive disorder (OCD) is characterized by obsessions (intrusive thoughts, images etc.) and compulsions (repetitive, stereotyped and perseverant acts). Compulsions are reported to relieve anxiety induced by the obsessions. However, the connection between them is usually poor or unreasonable [1]. A 1.2\% lifelong prevalence is reported [2] and increasing rates in first degree relatives, dizygotic and monozygotic twins point to an important role for genetic factors [1]. As the disorder can be debilitating, cognitive-behavioral or pharmacological therapies (selective serotonin reuptake inhibitors [SSRI] are first-line treatments) are usually applied; in some refractory cases neurosurgery offers some degree of symptoms relief [3].

Obsessions may involve decreased confidence in memory and biases toward threatening stimuli and memory [4] [5]. While it is not feasible to model obsessions in animals because of their cognitive nature, compulsions are especially suitable for this purpose. Further, it is argued elsewhere that "modeling compulsive behavior is a 
meaningful surrogate endpoint for an OCD model” [6].

To be considered satisfactory and useful, an animal model should attend some validation criteria. Those considered mostly important include [7]: face validity (How similar are the behavior under study and the clinical manifestations of the disorder?), construct validity (Are the behavioral and neurobiological processes involved in the model and in the disorder similar?) and predictive validity (Can the model predict the effect of a treatment in human patients?).

As compulsive behaviors are feasible targets for animal modeling, it is important to note that they can be viewed from different perspectives [8]: 1) as persistence in the face of adverse consequences; 2) as behavioral inflexibility; or, 3) as inability to monitor or stop behavior. Animals can show compulsive behaviors which parallel the description of compulsions for human patients in respect to their exaggerated and maladaptive nature. Indeed, for example, acral-lick dermatitis is seen in large-breed canines and other mammals and is characterized by excessive licking/biting of extremities. Similarly, when confined to captivity, different species frequently show stereotypy (e.g. vervet monkeys). In both examples, SSRI treatment is able to decrease the compulsive behavior [9] [10].

Since genetic factors seem to be involved in OCD, studying these factors in animal models is important both for the validation of the model and for improving knowledge about the disorder. A selective breeding program for phenotypes of increased or decreased amounts of a compulsive behavior could be a heuristic tool for studying OCD. Indeed, such kind of program was successfully achieved in respect to nest building behavior in mice [11]. No similar program, to the best of our knowledge, was developed using rats. However, comparing existing strains in animal models of OCD seems to be a valuable starting point. Many procedures were developed for modeling OCD (for reviews see [6] [12]). However, just a few were employed for investigating strain (and individual) differences. In the following sections, the available information about these differences is explored.

\section{Animal Models of OCD}

\subsection{Schedule-Induced Polydipsia}

Impressive increases in drinking behavior (more than a three-fold increase in relation to the regular 24-hour intake) during a 3-hour training session can be found as a result of the delivery of food pellets in an intermittent schedule to food-deprived rats [13]. As the procedure is carried out with non water-deprived animals, this phenomenon, known as schedule-induced polydipsia (SIP), is acknowledged as unrelated to homeostatic needs and, thus, seems to be marked by an exaggerated, repetitive and maladaptive drinking behavior. Indeed, SIP is proposed as an animal model of compulsion symptoms that can be useful for studying OCD. The fact that chronic treatment with SSRI leads to decreases in SIP (see [14] [15]) indicates that the model is provided with predictive validity for that disorder (for a review see [16]).

Schedule-induced polydipsia seems to be a behavioral process of great generality (however, for some limitations observed in wild-caught rats, see [17]). Nevertheless, some studies indicate differences in SIP among rat strains. For instance, Wistar and spontaneously hypertensive rats (SHR) are reported to present increased SIP when compared to Wistar Kyoto rats (WKY) [18]. Similarly, female inbred Roman high avoidance (RHA-I) rats, as compared to the inbred Roman low avoidance (RLA-I), also show increases in SIP [19] (these strains were selected for rapid [RHA-I] vs extremely poor [RLA-I] acquisition of two-way active avoidance response [20]). Curiously, a study comparing Lewis and Fisher rat strains demonstrated differences in females, but not in males. Fisher females present more SIP than males from the same strain and also than Lewis females [21].

An alternative approach for studying SIP in its possible relationship with genetic factors is the evaluation of naturally occurring differences in this behavior. For example, after 20 daily sessions, a sample of Wistar rats was divided into a high (HD) and a low drinker (LD) group. The criterion of being above or below the median (last three sessions) was used for grouping the rats. These groups were seen as clearly different from the fifth session onwards. Noteworthy, lower doses of $d$-amphetamine or cocaine (drugs that increase dopaminergic activity) are needed for decreasing SIP in HD than in LD rats [22]. Other studies have further contributed to establish relationships between individual differences in SIP and monoaminergic function in brain structures relevant for OCD [23] [24].

\subsection{Food-Restriction-Induced Hyperactivity}

When access to food is restricted to a short period a day (usually $90 \mathrm{~min}$ ), rats can stabilize their weight shortly 
after an initial drop. However, if a running wheel is available, activity in the wheel will progressively increase and, paradoxically, food intake will decrease. Running behavior plays an exaggerated and maladaptive role that resembles compulsive symptoms in OCD (face validity). Predictive validity is supported by the fact that chronic treatment with the SSRI fluoxetine is reported to prevent increases in wheel running and weight loss [25]. Food-restriction-induced hyperactivity (FRIH) is in fact also used as an animal model of anorexia nervosa. In this connection, it is important to note that OCD and anorexia nervosa have shared features (e.g. obsessions and compulsions) and are highly comorbid (see, for example [26]).

When this procedure was carried out with Fisher 344, Brown Norway and Lewis rats, these two later strains were found as more vulnerable to FRIH than the former one. Indeed, they showed increased wheel activity and reached the $25 \%$ body weight-loss criterion faster. Correspondingly, they also showed prefeeding increases in corticosterone, an effect not found in the Fisher 344 strain [27].

\subsection{Signal Attenuation}

In OCD, it is hypothesized that compulsive behaviors can occur due to a deficient psychological/neurobiological mechanism that would normally be responsible for "loop closure" between an action and its expected outcome [28]. That malfunctioning could account for maladaptive repetitive behaviors. The signal attenuation model (SAM) seems to replicate this feature of OCD through a complex procedure. Briefly, in an operant chamber, food restricted rats are provided with food pellets which are accompanied in each trial by a compound stimulus (light and tone). That simultaneous presentation is used for lever press training. This training is followed by "signal attenuation" sessions in which the compound stimulus is presented, but not accompanied by a food pellet. Finally, in the test session, bar presses are followed by the compound stimulus, but food is never delivered. As a result of the "signal attenuation" sessions, high rates of "extra lever presses in uncompleted trials" (ELP-U) are found (these lever presses are labeled "extra" because they occur in addition to an initial lever press in the trial and the trials are labeled "uncompleted" because in them the rat do not attempt to collect a reward) [29] [30]. The attenuated association between the compound stimulus and the reward (produced by pavlovian extinction during the "signal attenuation" sessions) stands as a sort of deficient (external) feedback about the outcome of a lever press. High rates of ELP-U resemble compulsion in OCD in that they are repetitive and maladaptive responses. Acute treatment with fluoxetine [29] and other SSRIs (for a review see [30]) before the test session is reported to decrease ELP-U, a fact that points to SAM as a suitable animal model of OCD.

While the SAM model was developed using Wistar rats, similar behavioral processes were also found in Sprague-Dawley and Lewis strains. Importantly, the Lewis inbred is derived from the Sprague-Dawley outbred strain. Thus, it is especially compelling that, among these strains, Lewis rats were found to present the highest ELP-U rates. Interestingly, while differing in these "compulsive” responses, Lewis and Sprague-Dawley are reported to show similar regular (i.e. with no previous signal attenuation) operant extinction [31].

\subsection{Hoarding Behavior}

Hoarding behavior consists of carrying different material from a point to the living place [32]. In humans, compulsive hoarding $(\mathrm{CH})$ is an obsessive-compulsive spectrum disorder characterized by difficulties in discarding several types of objects [1]. Similarly to other obsessive-compulsive spectrum disorders, $\mathrm{CH}$ is associated to a deficiency in mechanisms that inhibits normal hoard [33] [34]. Pharmacotherapy for $\mathrm{CH}$, however, is different from that for other obsessive-compulsive spectrum disorders-it comprises administration of dopaminergic D2 antagonists (SSRI do not alleviate the symptoms) [35]. A procedure using rats resembles human CH. The equipment consists of a home-cage connected to a walled alley. Food pellets are available in the alley. The amount of food carried to the home cage is the parameter used for studying $\mathrm{CH}$. Treating rats with D2 antagonists was reported to decrease the amount of pellets collected-SSRIs, on the other hand, have no effects [36]. Furthermore, 6-hydroxydopamine lesion of mesolimbic projections abolishes pellet gathering and this effect can be reversed by L-dopa [37]. Parallels between this model and human CH disorder suggest that the former is provided with face and predictive validity.

Hoarding behavior was largely studied during the mid $-20^{\text {th }}$ century. Despite this early attention, few studies were found comparing different strains. Black-hooded rats are reported to gather more pellets than brownhooded and Irish rats [38]. In other comparisons, Wistar rats were found to gather more pellets than the animals from the black and brown-hooded strains [39] and than those from the pigmented lister hooded strain [40]. 


\subsection{Grooming Behavior}

Establishing parallels between rat grooming behavior and OCD symptoms seems to be quite intuitive. Indeed, in its appearance, grooming is repetitive, stereotyped and perseverant [41]. Further, in spite of generally playing the function of caring for the skin/fur, grooming can be elicited by situations not related to skin condition-interestingly, grooming occurrence can be exacerbated by stressful experiences [42]. Thus, grooming behavior seems to be repetitive and maladaptive, mimicking characteristics of compulsive symptoms in OCD patients. Some evidences (most from studies using mice) indicate that the striatum plays a key role in modulating this behavior (see, for example [43]-[45]). Despite the apparent obviousness of parallels between rodent grooming and OCD symptoms, carrying out these parallels in experimental studies can be a rather tricky task.

For instance, some reports describe decreases in mice grooming after treatment with the SSRI fluoxetine [44] [46]. On the other hand, after exposure to unpredictable chronic mild stress, fluoxetine can increase grooming, reversing the effects of the stress regimen [47]. These findings are generally in accordance with observations that effects on grooming can occur in a context-dependent manner, i.e. they can appear or not (or can be even opposite), depending of the test situation (see, for example [43] [48]). The above information can be seen as warning notes on the complexity of interpreting grooming results.

Strain differences in grooming were studied in depth in comparisons between the RHA and the RLA lines/strains. These lines/strains, after selection for rapid or poor acquisition of two-way active avoidance, were found to differ in many domains, the RLA being much more anxious/fearful, frustration-prone and stress-prone than the RHA (see, for example [49] [50]). RLA rats are reported to present increased grooming in anxiety tests such as the Vogel's conflict and the hyponeophagia test [51], as well as in the open field and the elevated plus-maze [52]. In another study in which the inbred RLA-I and RHA-I were compared, the former is reported to show increases in grooming in the open field and in the hole-board. However, no differences were found in home-cage and an apparent opposite difference was found during a two-way active avoidance task [48].

\section{Conclusions}

Many procedures have been proposed as useful models of OCD. However, just a few were used for evaluating strain differences (or even individual differences). The procedures are remarkably different in how they induce compulsive behaviors and in what behaviors are seen as compulsive. Taking this into account, it is not surprising that, when the same strains were compared in different procedures, different and even opposite results were found in some cases (Table 1 ).

This is the case for the Lewis and Fisher 344 strains. In the SIP model, Fisher rats are found as more "compulsive". In the FRIH, on the other hand, the Lewis strain is in evidence-further confirmed in other model, the SAM. A similar position replacement is found in comparisons between the RHA-I and the RLA-I strains: the former seems to be more "compulsive" according to the SIP model, the later according to grooming behavior under novelty.

Looking at the shared features of the most "compulsive" strains, it is remarkable the recurrence of themes such as drug- or novelty-seeking and decreased anxiety. These are points about the evaluated animal models hard to reconcile with human OCD and its recognized relationship with anxiety [1]. For the future it is expected

Table 1. Differences between pairs of rat strains in animal models of obsessive-compulsive disorder.

\begin{tabular}{|c|c|c|c|}
\hline Procedure & Strain & Remarks about the "most compulsive" strains & References \\
\hline \multirow[t]{3}{*}{$\begin{array}{l}\text { Schedule-induced } \\
\text { polydipsia }\end{array}$} & SHR > Wistar Kyoti & $\begin{array}{l}\text { Hypertension, decreased anxiety and nociception, } \\
\text { hyperactivity }\end{array}$ & {$[18][53][54]$} \\
\hline & Fisher $344>$ Lewis $^{1}$ & Decreased anxiety & {$[21][55]$} \\
\hline & RHA-I > RLA-I ${ }^{2}$ & Novelty-seeking, impulsivity & {$[19]$} \\
\hline $\begin{array}{l}\text { Food-restriction-induced } \\
\text { hyperactivity }\end{array}$ & Lewis > Fisher 344 & $\begin{array}{c}\text { Inflammation susceptibility, blunted endocrine stress } \\
\text { response, drug-seeking }\end{array}$ & {$[27][56][57]$} \\
\hline Signal attenuation & Lewis > Sprague-Dawley & $\begin{array}{c}\text { Inflammation susceptibility, blunted endocrine stress } \\
\text { response, drug-seeking }\end{array}$ & {$[27][56][57]$} \\
\hline Grooming behavior ${ }^{3}$ & RLA-I > RHA-I & Fearfulness, frustration, stress reactivity & {$[49][50]$} \\
\hline
\end{tabular}

${ }^{1}$ difference found in females, but not in males; ${ }^{2}$ only females were compared; ${ }^{3}$ in conflict and novelty anxiety tests. 
that other comparisons among strains in different animal models of OCD can further improve knowledge about the disorder and reveal nuances about the behavioral processes in the disorder not accessible in other types of approaches.

\section{Acknowledgements}

This investigation was supported by CNPq (proc. 483937/2011-8) and T. P. Maio received a fellowship from CAPES.

\section{References}

[1] American Psychiatric Association (2013) Diagnostic and Statistical Manual of Mental Disorders. 5th Edition, American Psychiatric Publishing, Arlington.

[2] Kessler, R.C., Berglund, P., Demler, O., Jin, R., Merikangas, K.R., et al. (2005) Lifetime Prevalence and Age-of-Onset Distributions of DSM-IV Disorders in the National Comorbidity Survey Replication. Archives of General Psychiatry, 62, 593-602. http://dx.doi.org/10.1001/archpsyc.62.6.593

[3] Dougherty, D.D. (2002) Prospective Long-Term Follow-Up of 44 Patients Who Received Cingulotomy for TreatmentRefractory Obsessive-Compulsive Disorder. The American Journal of Psychiatry, 159, 269-275. http://dx.doi.org/10.1176/appi.ajp.159.2.269

[4] Deckarsbach, T., Otto, M.W., Savage, C.R., Baer, L. and Jenike, M.A. (2000) The Relationship between Semantic Organization and Memory in Obsessive-Compulsive Disorder. Psychotherapy and Psychosomatics, 69, 101-107. http://dx.doi.org/10.1159/000012373

[5] Rao, N.P., Arasappa, R., Reddy, N.N., Venkatasubramanian, G. and Reddy, Y.C.J. (2010) Emotional Interference in Obsessive-Compulsive Disorder: A Neuropsychological Study Using Optimized Emotional Stroop Test. Psychiatry Research, 180, 99-104. http://dx.doi.org/10.1016/j.psychres.2009.10.017

[6] Korff, S. and Harvey, H. (2006) Animal Models of Obsessive-Compulsive Disorder: Rationale to Understanding Psychobiology Ad Pharmacology. Psychiatric Clinics of North America, 29, 371-390.

http://dx.doi.org/10.1016/j.psc.2006.02.007

[7] Geyer, M.A. and Markou, A. (1995) Animal Models of Psychiatric Disorders. In: Bloom, F. and Kupfer, D., Eds., Psychopharmacology: The Fourth Generation of Progress, Raven Press, New York, 787-798.

[8] Fernando, A.B.P. and Robbins, T.W. (2011). Animal Models of Neuropsychiatric Disorders. Annual Review of Clinical Psychology, 7, 39-61. http://dx.doi.org/10.1146/annurev-clinpsy-032210-104454

[9] Hugo, C., Seier, J., Mdhluli, C., Daniels, W., Harvey, B.H., et al. (2003) Fluoxetine Decreases Stereotypic Behavior in Primates. Progress in Neuro-Psychopharmacology and Biological Psychiatry, 27, 639-643. http://dx.doi.org/10.1016/S0278-5846(03)00073-3

[10] Rapaport, J.L., Ryland, D.H. and Kriete, M. (1992) Drug Treatment of Canine Acral Lick—An Animal Model of Obsessive-Compulsive Disorder. Archives in General Psychiatry, 49, 517-521. http://dx.doi.org/10.1001/archpsyc.1992.01820070011002

[11] Greene-Schloesser, D.M., Van der Zee, E.A., Sheppard, D.K., Castillo, M.R., Gregg, K.A., et al. (2011) Predictive Validity of a Non-Induced Mouse Model of Compulsive-Like Behavior. Behavioural Brain Research, 221, 55-62. http://dx.doi.org/10.1016/j.bbr.2011.02.010

[12] Hoffman, K.J. (2011) Animal Models of Obsessive Compulsive Disorder: Recent Findings and Future Directions. Expert Opinion on Drug Discovery, 6, 725-737. http://dx.doi.org/10.1517/17460441.2011.577772

[13] Falk, J.L. (1961) Production of Polydipsia in Normal Rats by an Intermittent Food Schedule. Science, 133, 195-196. http://dx.doi.org/10.1126/science.133.3447.195

[14] Hogg, S. and Dalvi, A. (2004) Acceleration of Onset of Action in Schedule-Induced Polydipsia: Combinations of SSRI and 5-HT1A and 5-HT1B Receptor Antagonists. Pharmacology Biochemistry and Behavior, 77, 69-75. http://dx.doi.org/10.1016/j.pbb.2003.09.020

[15] Woods, A., Smith, C., Szewczac, M., Dunn, R.W., Cornfeldt, M., et al. (1993) Selective Serotonin Re-Uptake Inhibitors Decrease Schedule-Induced Polydipsia in Rats: A Potential Model for Obsessive Compulsive Disorder. Psychopharmacology, 112, 195-198. http://dx.doi.org/10.1007/BF02244910

[16] Moreno, M. and Flores, P. (2012) Schedule-Induced Polydipsia as a Model of Compulsive Behavior: Neuropharmacological and Neuroendocrine Bases. Psychopharmacology, 219, 647-659. http://dx.doi.org/10.1007/s00213-011-2570-3

[17] McCaffrey, R.J., Pavlik, M.K., Hoppman, R.A. and Allen, J.D. (1980) A Parametric Investigation into the Generality 
of Schedule-Induced Polydipsia to Wild-Caught Norway and Wild-Caught Cotton Rats. Physiology \& Behavior, 24, 457-461. http://dx.doi.org/10.1016/0031-9384(80)90236-X

[18] Ibias, J. and Pellón, R. (2011) Schedule-Induced Polydipsia in the Spontaneously Hypertensive Rat and Its Relation to Impulsive Behavior. Behavioural Brain Research, 223, 58-69. http://dx.doi.org/10.1016/j.bbr.2011.04.017

[19] Moreno, M., Cardona, D., Gomez, M.J., Sánchez-Santed, F., Tobeña, A., et al. (2010) Impulsivity Characterization in the Roman High- and Low-Avoidance Rat Strains: Behavioural and Neurochemical Differences. Neuropsychopharmacology, 35, 1198-1208. http://dx.doi.org/10.1038/npp.2009.224

[20] Driscoll, P., Escorihuela, R.M., Fernández-Teruel, A., Giorgi, O., Schwegler, H., et al. (1998) Genetic Selection and Differential Stress Responses: The Roman Lines/Strains of Rats. Annals of the New York Academy of Sciences, 851, 501-510. http://dx.doi.org/10.1111/j.1749-6632.1998.tb09029.x

[21] Stöhr, T., Szuran, T., Welzl, H., Pliska, V., Feldon, J. and Pryce, C.R. (2000) Lewis/Fischer Rat Strain Differences in Endocrine and Behavioural Responses to Environmental Challenge. Pharmacology Biochemistry and Behavior, 67, 809-819. http://dx.doi.org/10.1016/S0091-3057(00)00426-3

[22] López-Grancha, M., Lopez-Crespo, G., Sanches-Amate, M.C. and Flores, P. (2008) Individual Differences in Schedule-Induced Polydipsia and the Role of Gabaergic and Dopaminergic Systems. Psychopharmacology, 197, 487-498. http://dx.doi.org/10.1007/s00213-007-1059-6

[23] Pellón, R., Ruíz, A., Moreno, M., Claro, F., Ambrosio, E. and Flores, P. (2011) Individual Differences in ScheduleInduced Polydipsia: Neuroanatomical Dopamine Divergences. Behavioural Brain Research, 217, 195-201. http://dx.doi.org/10.1016/j.bbr.2010.10.010

[24] Moreno, M., Gutiérrez-Ferre, V.E., Ruedas, L., Campa, L., Suñol, C. and Flores, P. (2012) Poor Inhibitory Control and Neurochemical Differences in High Compulsive Drinker Rats Selected by Schedule-Induced Polydipsia. Psychopharmacology, 219, 661-672. http://dx.doi.org/10.1007/s00213-011-2575-y

[25] Altemus, M., Glowa, J.R., Galliven, E., Leong, Y.M. and Murphy, D.L. (1996) Effects of Serotonergic Agents on Food-Restriction-Induced Hyperactivity. Pharmacology Biochemistry and Behavior, 53, 123-131. http://dx.doi.org/10.1016/0091-3057(95)02003-9

[26] Davis, C. and Kaptein, S. (2006) Anorexia Nervosa with Excessive Exercise: A Phenotype with Close Links to Obsessive-Compulsive Disorder. Psychiatry Research, 142, 209-217. http://dx.doi.org/10.1016/j.psychres.2005.11.006

[27] Duclos, M., Bouchet, M., Vettier, A. and Richard, D. (2005) Genetic Differences in Hypothalamic-Pituitary-Adrenal Axis Activity and Food Restriction-Induced Hyperactivity in Three Inbred Strains of Rats. Journal of Neuroendocrinology, 17, 740-752. http://dx.doi.org/10.1111/j.1365-2826.2005.01367.x

[28] Graybiel, A.M. and Rauch, S.L. (2000) Toward a Neurobiology of Obsessive-Compulsive Disorder. Neuron, 28, 343347. http://dx.doi.org/10.1016/S0896-6273(00)00113-6

[29] Joel, D. and Avisar, A. (2001) Excessive Lever Pressing Following Post-Training Signal Attenuation in Rats: A Possible Animal Model of Obsessive Compulsive Disorder? Behavioural Brain Research, 123, 77-87. http://dx.doi.org/10.1016/S0166-4328(01)00201-7

[30] Joel, D. (2006) The Signal Attenuation Rat Model of Obsessive-Compulsive Disorder: A Review. Psychopharmacology, 186, 487-503. http://dx.doi.org/10.1007/s00213-006-0387-2

[31] Brimberg, L., Flaisher-Grinberg, S., Schilman, E.A. and Joel, D. (2007) Strain Differences in 'Compulsive' Lever-Pressing. Behavioural Brain Research, 179, 141-151. http://dx.doi.org/10.1016/j.bbr.2007.01.014

[32] Ross, S., Smith, W.I. and Woessner, B.L. (1955) Hoarding: An Analysis of Experiments and Trends. Journal of General Psycholoy, 52, 307-326. http://dx.doi.org/10.1080/00221309.1955.9920246

[33] Stam, C.J., Bruin, J.P., van Haelst, A.M., van der Gugten, J. and Kalsbeek, A. (1989) Influence of the Mesocortical Dopaminergic Systm on Activity, Food Hoarding, Social-Agonistic Behavior, and Spatial Delayed Alternation in Male Rats. Behavioral Neuroscience, 103, 24-35. http://dx.doi.org/10.1037/0735-7044.103.1.24

[34] Anderson, S.W., Damasio, H. and Damasio, A.R. (2005) A Neural Basis for Collecting Behaviour in Humans. Brain, 128, 201-212. http://dx.doi.org/10.1093/brain/awh329

[35] Saxena, S. (2011) Pharmacotherapy of Compulsive Hoarding. Journal of Clinical Psychology, 67, 477-484. http://dx.doi.org/10.1002/jclp.20792

[36] Andrew-McClymont, J.G., Lilienfeld, S.O. and Duke, M.P. (2013) Evaluating an Animal Model of Compulsive Hoarding in Humans. Review of General Psychology, 17, 399-419. http://dx.doi.org/10.1037/a0032261

[37] Kelley, A.E. and Stinus, L. (1985) Disappearance of Hoarding Behavior after 6-Hydroxydopamine Lesions of the Mesolimbic Dopamine Neurons and Its Reinstatement with L-Dopa. Behavioral Neuroscience, 99, 531-545. http://dx.doi.org/10.1037/0735-7044.99.3.531

[38] Stamm, J.S. (1954) Genetics of Hoarding. I. Hoarding Differences between Homozygous Strains of Rats. Journal of 
Comparative and Physiological Psychology, 47, 157-161. http://dx.doi.org/10.1037/h0054863

[39] Rebouças, R.C. and Schmidek, W.R. (1997) Handling and Isolation in Three Strains of Rats Affect Open Field, Exploration, Hoarding and Predation. Physiology \& Behavior, 62, 1159-1164. http://dx.doi.org/10.1016/S0031-9384(97)00312-0

[40] Broersen, L.M. and Uylings, H.B. (1999) Visual Attention Task Performance in Wistar and Lister Hooded Rats: Response Inhibition Deficits after Medial Prefrontal Cortex Lesions. Neuroscience, 94, 47-57. http://dx.doi.org/10.1016/S0306-4522(99)00312-7

[41] Berridge, K.C., Fentress, J.C. and Parr, H. (1987) Natural Syntax Rules Control Action Sequence of Rats. Behavioural Brain Research, 23, 59-68. http://dx.doi.org/10.1016/0166-4328(87)90242-7

[42] Spruijt, B., Van Hooff, J. and Gispen, W. (1992) Ethology and Neurobiology of Grooming Behavior. Physiological Reviews, 72, 825-852.

[43] Berridge, K.C., Aldridge, J.W., Houchard, K.R. and Zhuang, X.X. (2005) Sequential Super-Stereotypy of an Instinctive Fixed Action Pattern in Hyper-Dopaminergic Mutant Mice: A Model of Obsessive Compulsive Disorder and Tourette’s. BMC Biology, 3, 4. http://dx.doi.org/10.1186/1741-7007-3-4

[44] Welch, J.M., Lu, J., Rodriguiz, R.M., Trotta, N.C., Peca, J., et al. (2007) Cortico-Striatal Synaptic Defects and OCDLike Behaviours in Sapap3-Mutant Mice. Nature, 448, 894-900. http://dx.doi.org/10.1038/nature06104

[45] Greer, J.M. and Capecchi, M.R. (2002) Hoxb8 Is Required for Normal Grooming Behavior in Mice. Neuron, 33, $23-34$. http://dx.doi.org/10.1016/S0896-6273(01)00564-5

[46] Ahmari, S.E., Spellman, T., Douglass, N.L., Kheirbek, M.A., Simpson, H.B., et al. (2013) Repeated Cortico-Striatal Stimulation Generates Persistent OCD-Like Behavior. Science, 340, 1234-1239. http://dx.doi.org/10.1126/science.1234733

[47] Surget, A., Saxe, M., Leman, S., Ibarguen-Vargas, Y., Chalon, S., et al. (2008) Drug-Dependent Requirement of Hippocampal Neurogenesis in a Model of Depression and of Antidepressant Reversal. Biological Psychiatry, 64, 293-301. http://dx.doi.org/10.1016/j.biopsych.2008.02.022

[48] Estanislau, C., Díaz-Morán, S., Cañete, T., Blázquez, G., Tobeña, A. and Fernández-Teruel, A. (2013) Context-Dependent Differences in Grooming Behavior among the NIH Heterogeneous Stock and the Roman High- and LowAvoidance Rats. Neuroscience Research, 77, 187-201. http://dx.doi.org/10.1016/j.neures.2013.09.012

[49] Díaz-Morán, S., Palència, M., Mont-Cardona, C., Cañete, T., Blázquez, G., et al. (2012) Coping Style and Stress Hormone Responses in Genetically Heterogeneous Rats: Comparison with the Roman Rat Strains. Behavioural Brain Research, 228, 203-210. http://dx.doi.org/10.1016/j.bbr.2011.12.002

[50] Steimer, T. and Driscoll, P. (2003) Divergent Stress Responses and Coping Styles in Psychogenetically Selected Roman High-(RHA) and Low-(RLA) Avoidance Rats: Behavioural, Neuroendocrine and Developmental Aspects. Stress, 6, 87-100. http://dx.doi.org/10.1080/1025389031000111320

[51] Ferré, P., Fernández-Teruel, A., Escorihuela, R.M., Driscoll, P., Corda, M.G., Giorgi, O. and Tobeña, A. (1995) Behavior of the Roman/Verh High- and Low-Avoidance Rat Lines in Anxiety Tests: Relationship with Defecation and SelfGrooming. Physiology \& Behavior, 58, 1209-1213. http://dx.doi.org/10.1016/0031-9384(95)02068-3

[52] Escorihuela, R.M., Fernández-Teruel, A., Gil, L., Aguilar, R., Tobeña, A., et al. (1999) Inbred Roman High- and Low-Avoidance Rats: Differences in Anxiety, Novelty-Seeking, and Shuttlebox Behaviors. Physiology \& Behavior, 67, 19-26. http://dx.doi.org/10.1016/S0031-9384(99)00064-5

[53] Ramos, A., Kangerski, A.L., Basso, P.F., Da Silva Santos, J.E., Assreuy, J., et al. (2002) Evaluation of Lewis and SHR Rat Strains as a Genetic Model for the Study of Anxiety and Pain. Behavioural Brain Research, 129, 113-123. http://dx.doi.org/10.1016/S0166-4328(01)00337-0

[54] Sagvolden, T., Metzger, M.A., Schiorbeck, H.K., Rugland, A.L., Spinnangr, I., et al. (1992) The Spontaneously Hypertensive Rat (SHR) as an Animal Model of Childhood Hyperactivity (ADHD): Changed Reactivity to Reinforcers and to Psychomotor Stimulants. Behavioral and Neural Biology, 58, 103-112. http://dx.doi.org/10.1016/0163-1047(92)90315-U

[55] Glowa, J.R. and Hansen, C.T. (1994) Differences in Response to an Acoustic Startle Stimulus among Forty-Six Rat Strains. Behavior Genetics, 24, 79-84. http://dx.doi.org/10.1007/BF01067931

[56] Sternberg, E.M., Hill, J.M., Chrousos, G.P., Kamilaris, T., Listwak, S.J., et al. (1989) Inflammatory Mediator-Induced Hypothalamic-Pituitary-Adrenal Axis Activation Is Defective in Streptococcal Cell Wall Arthritis-Susceptible Lewis Rats. Proceedings of the National Academy of Sciences of the United States of America, 86, 2374-2378. http://dx.doi.org/10.1073/pnas.86.7.2374

[57] George, F.R. (1990) Genetic Approaches to Studying Drug Abuse: Correlates of Drug Self-Administration. Alcohol, 7, 207-211. http://dx.doi.org/10.1016/0741-8329(90)90006-X 